\title{
Coevolutionary fine-tuning: evidence for genetic tracking between a specialist wasp parasitoid and its aphid host in a dual metapopulation interaction
}

\author{
F.N. Nyabuga ${ }^{1,2+*}$, H.D. Loxdale ${ }^{1,2}$, D.G. Heckel ${ }^{2}$ \\ and W.W. Weisser ${ }^{1}$ \\ ${ }^{1}$ Institute of Ecology, Friedrich Schiller University, Dornburger Strasse 159, \\ 07743 Jena, Germany: ${ }^{2}$ Department of Entomology, Max Planck Institute for \\ Chemical Ecology, Hans-Knöll-Strasse 8, 07745 Jena, Germany
}

\begin{abstract}
In the interaction between two ecologically-associated species, the population structure of one species may affect the population structure of the other. Here, we examine the population structures of the aphid Metopeurum fuscoviride, a specialist on tansy Tanacetum vulgare, and its specialist primary hymenopterous parasitoid Lysiphlebus hirticornis, both of which are characterized by multivoltine life histories and a classic metapopulation structure. Samples of the aphid host and the parasitoid were collected from eight sites in and around Jena, Germany, where both insect species co-occur, and then were genotyped using suites of polymorphic microsatellite markers. The host aphid was greatly differentiated in terms of its spatial population genetic patterning, while the parasitoid was, in comparison, only moderately differentiated. There was a positive Mantel test correlation between pairwise shared allele distance $(D A S)$ of the host and parasitoid, i.e. if host subpopulation samples were more similar between two particular sites, so were the parasitoid subpopulation samples. We argue that while the differences in the levels of genetic differentiation are due to the differences in the biology of the species, the correlations between host and parasitoid are indicative of dependence of the parasitoid population structure on that of its aphid host. The parasitoid is genetically tracking behind the aphid host, as can be expected in a classic metapopulation structure where host persistence depends on a delay between host and parasitoid colonization of the patch. The results may also have relevance to the Red Queen hypothesis, whereupon in the 'arms race' between parasitoid and its host, the latter 'attempts' to evolve away from the former.
\end{abstract}

Keywords: aphid, Metopeurum fuscoviride, hymenopterous parasitoid, Lysiphlebus hirticornis, tansy plant, Tanacetum vulgare, specialist, genetic variability, genetic tracking, metapopulation

(Accepted 2 August 2011; First published online 27 September 2011)

*Author for correspondence

Fax: + 46-40-46 2166

E-mail: franklin.nyabuga@slu.se

tCurrent address: Department of Plant Protection Biology, Swedish University of Agricultural Sciences, Box 102, SE-230 53 Alnarp,

Sweden 


\section{Introduction}

The geographic structure of interacting species is a major component of evolving interactions and coevolutionary processes (Thompson, 1994). Evolutionary processes of differential selection, mating structure and gene flow in subdivided populations all contribute in creating genetic variance among geographic mosaics of populations. Consequently, understanding the geographic structure of species helps to elucidate species interactions and levels of adaptation that may not be identical over entire species ranges (e.g. Kraaijeveld \& van der Wel, 1994; Kraaijeveld \& Van Alphen, 1995).

The population genetics of insects may be influenced by interactions among species, and one of the strongest interactions is between hosts and their parasitoids. Thus, Kankare et al. (2005) noted that comparing such interacting species inhabiting the same landscape was a powerful approach to studying spatial population structures. This is because, in these cases, possible differences are due to biological properties of the species rather than to particular features of the environment. A few studies have to date compared the spatial genetic structures of closely interacting species, especially between a host and its parasitoid (but see Althoff \& Thompson, 1999; Johannesen \& Seitz, 2003; Anton et al., 2007), although only the latter two studies within a metapopulation context.

For example, Anton et al. (2007) found higher overall genetic differentiation in the specialist univoltine parasitoid Neotypus melanocephalus Gmelin (Hymenoptera: Ichneumonidae), compared with its univoltine host, the Dusky large blue butterfly, Maculinea nausithous (Bergsträsser) (Lepidoptera: Lycaenidae). Mantel test correlations of pairwise genetic distances between butterfly populations were, however, not correlated with the genetic distances of corresponding pairs of parasitoid populations. The authors concluded that the observed differences are apparently due to the differences in breeding system, i.e. diploid host vs a haplodiploid parasitoid. Similarly, Johannesen \& Seitz (2003) simultaneously examined the population genetic structures of the univoltine gall forming fly, Urophora cardui (L.) (Diptera: Tephritidae), and its primary univoltine oligophagous parasitoid, Eurytoma robusta Mayr (Hymenoptera: Eurytomidae). While they found higher genetic structuring in populations of $E$. robusta than in the host populations and positive significant $F_{\mathrm{ST}}$ correlations between population pairs of the two insect species, they used standard regression measures which potentially inflate the degrees of freedom. While the metapopulation structure of the host will influence the population genetics of the parasitoid (Nyabuga et al., 2010), it remains unclear if the close interaction between host and parasitoid also leads to similar patterns of genetic differentiation between particular subpopulations.

To investigate this possibility, we used the same insect host-parasitoid system as previously used by Nyabuga et al. (2010, 2011), namely the specialist wasp parasitoid Lysiphlebus hirticornis Mackauer (Hymenoptera: Braconidae: Aphidiinae) attacking the holocyclic aphid, Metopeurum fuscoviride Stroyan (Hemiptera: Aphididae), which feeds exclusively on tansy, Tanacetum vulgare L. (Family Asteraceae $=$ Compositae) (see Massonnet, 2002; Loxdale et al., 2010, in press).

The L. hirticornis-M. fuscoviride system has a classic metapopulation structure (Weisser, 2000; Zheng et al., 2009).
In a field study, Weisser (2000) and Nyabuga et al. (2011) reported frequent extinction events for M. fuscoviride and, as a direct consequence, extinction too of the parasitoid L. hirticornis at the level of tansy plants (genets and ramets). At the local (site) spatial scale, Weisser (2000) and Nyabuga et al. (2010) found that many tansy plants were not colonized by the aphid and many tansy genets hosting the aphid were not colonized by the parasitoid. In further support of the view that $M$. fuscoviride has a metapopulation structure, Massonnet (2002), using six microsatellite markers to study seven subpopulations (five from the Alsace region of France and two from Germany), reported high population differentiation: pairwise $F_{S T}$ values ranged from 0.029 to $0.416($ mean $=0.222)$ and, of the 21 pairwise $F_{\mathrm{ST}}$ comparisons, 18 were significant $(P<0.05)$, a finding recently supported by Loxdale et al. (in press) who report such high (or higher) values for $M$. fuscoviride, even at a small spatial scale in and around Jena $\left(<80 \mathrm{~km}^{2}\right)$ using essentially the same suite of microsatellites. Similarly, Nyabuga et al. (2010), using 11 microsatellite markers on 11 subpopulations of L. hirticornis collected at a small spatial scale (the furthest sites being around $15 \mathrm{~km}$ apart) from $M$. fuscoviride colonies on tansy, also in and around Jena, found significant pairwise genetic differentiation between all subpopulations, with $F_{\mathrm{ST}}$ values ranging from 0.065 to 0.236 (mean $=0.148$ ). This finding strongly supports the view that the parasitoid has a local metapopulation structure like its host aphid and presumably is dependent to a greater extent on that of its host.

Both species also show various degrees of inbreeding and philopatry (Nyabuga et al., 2010, 2011; Loxdale et al., in press). The aphid M. fuscoviride and its parasitoid L. hirticornis have short and overlapping multivoltine lifecycles. The aphid produces overwintering eggs on tansy that hatch in spring and give rise to the fundatrix morph, i.e. first asexual stem mother (Massonnet, 2002). Thereafter, these fundatrix morphs give birth asexually by apomictic (=mitotic) parthenogenetic reproduction to asexual female offspring that develop to adulthood and start producing their own young in around ten days. As the growing season continues and the tansy plants begin to senesce towards autumn, wingless sexual females and wingless males are produced that mate and lay overwintering eggs, probably mostly on the same plant or nearby. Due to this type of reproduction, positive inbreeding coefficients $\left(F_{\mathrm{IS}}\right)$ in spatial units and high genetic diversity at the start of the annual season (in spring) that reduces to their lowest in autumn are reported (Massonnet, 2002; Loxdale et al., in press).

In contrast, the parasitoid L. hirticornis has a haplodiploid system whereby unfertilized eggs give rise to winged male offspring, while the mated and fertilized females produce winged females. It attacks aggregated aphids (colonies) and will oviposit eggs in the same aphid colony until virtually all available hosts are parasitized or it becomes egg limited (Mackauer \& Völkl, 2002). This sort of behaviour is thought to encourage inbreeding as inferred from microsatellite results (Nyabuga et al., 2010, 2011) and behavioral experiments (Nyabuga et al., in press). Under field conditions, egg oviposition to adult emergence takes $<16$ days. Parasitized adult aphids continue to produce young for some time until 'total castration' occurs (Polaszek, 1986).

In the present study, we hypothesize that the genetic differentiation of the aphid $M$. fuscoviride population structuring has a direct and congruent effect on its specialist parasitoid L. hirticornis population structure. Specifically we ask: (i) How 


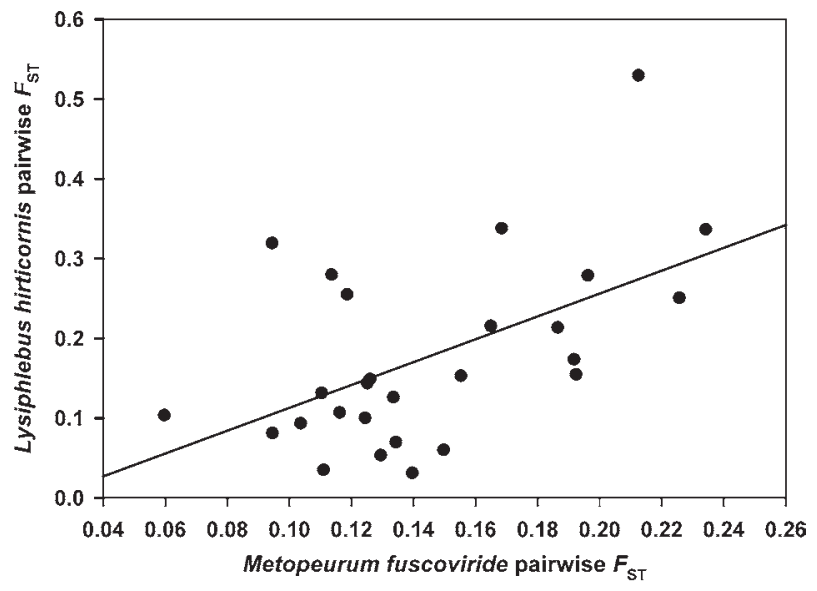

Fig. 1. Subpopulation differentiation, pairwise $F_{\mathrm{ST}}$, in Metopeurum fuscoviride was positively and linearly correlated to subpopulation differentiation in the parasitoid Lysiphlebus hirticornis $(\mathrm{R}=0.524$, $P=0.004)$

does the level of population genetic differentiation in the parasitoid compare to that of its aphid host? and (ii), Is there a relationship between the level of parasitoid population genetic differentiation and that of its aphid host?

\section{Material and methods}

\section{Field sites}

The population genetics of M. fuscoviride and its parasitoid L. hirticornis were studied between early June and late October, 2007 from 11 sites in and around Jena, Germany $\left(50^{\circ} 54^{\prime} \mathrm{N}, 11^{\circ}\right.$ $35^{\prime} \mathrm{E}$; see fig. 1 and appendix 1 in Nyabuga et al., 2010 for site details), all of which comprised waste grounds, especially land adjoining the railway track along the river Saale valley. Aphid and parasitoid samples in the form of aphid 'mummies' (developing parasitoid larvae/pupae within the aphid cuticle) were collected. Due to constraints in the number of individuals genotyped of either the aphid or parasitoid, eight sites were compared. We refer to all individuals from one site as a 'subpopulation', i.e. samples from eight host and eight parasitoid subpopulations were sampled.

\section{Field surveys and subpopulation sampling}

Tansy genets were visited and inspected at all sites for $M$. fuscoviride approximately every ten days throughout the growing season. If colonized by aphids, the genet was hand labelled and its phenology (shooting, flowering, senescing, etc.) noted; the numbers of ramets per genet were counted along with the number of ramets colonized by the aphid. Each aphid colony was estimated for size and further inspected for aphid mummies. The L. hirticornis aphid mummies' dark brownish coloration easily distinguished them from other parasitoid species attacking $M$. fuscoviride, in particular Aphidius tanacetarius Mackauer and Ephedrus Haliday spp. (Hymenoptera: Braconidae: Aphidiinae). During subsequent visits, the fate of marked genets with aphid colonies was followed and any new genet colonization marked and recorded. The study continued for the entire growing season, until the shoots senesced and the aphid colonies collapsed (for detailed description of sampling method and results, see Nyabuga et al., 2010, 2011).

Sample collection and analysis by microsatellites Aphids

Collected aphids were placed into $100 \%$ ethanol in $1.5 \mathrm{ml}$ Eppendorf tubes and stored refrigerated $\left(\sim 4^{\circ} \mathrm{C}\right)$ until DNA extraction. Purified DNA was stored deep frozen at $-20^{\circ} \mathrm{C}$, as was that of parasitoids (see below). To maximize genetic heterogeneity, usually only 1-5 aphids were tested per tansy ramet. Aphids were visually checked during sorting (also in $100 \%$ ethanol), and those obviously parasitized by braconid wasps or contaminated with entomopathogenic fungi were discarded. DNA was extracted from individual $M$. fuscoviride aphids using the 'salting out' procedure of Sunnucks \& Hales (1996). Microsatellite banding profiles were obtained using the five primers (Mf- 1 to -5 ) and protocols essentially as detailed by Massonnet et al. (2002) (see also Loxdale et al., in press). Briefly, 10- $\mu$ l reaction mixture volumes had a final $\mathrm{Mg}^{2+}$ concentration of $1.5 \mathrm{mM}$, and PCR reactions were performed using Eppendorf thermocyclers (Mastercycler ${ }^{\circledR}$ ). PCR products were detected on a Licor 4300 sequencer using $0.25 \mathrm{~mm}$ thick, $6.5 \%$ polyacrylamide gels and IRD700 and IRD800 fluorescently labelled forward primers. 50-350 bp IRD700 and IRD800 fluorescently-labelled size markers were used to determine product size.

\section{Parasitoids}

For each site, between five and a maximum of ten L. hirticornis aphid mummies were sampled from tansy plants. Sampling was also done between early June and late October, 2007. The aphid mummies were collected in $1.5 \mathrm{ml}$ Eppendorf tubes for transport to the laboratory where the winged adult parasitoids were left to emerge and their sex determined under a stereo binocular microscope. Males and females from a single genet were stored separately in Eppendorfs in 100\% ethanol at $4{ }^{\circ} \mathrm{C}$ prior to DNA extraction. For genetic analyses, only female parasitoids were used. As with the aphids, DNA was extracted using the 'salting-out' method. Eleven microsatellite loci, namely Lhirt01, Lhirt02, Lhirt03, Lhirt04, Lhirt06, Lhirt08, Lhirt10, Lhirt15, Lhirt23, Lysi08 and Lysi6b12, were used. These loci, along with the PCR, sequencing and scoring procedures used are detailed in Nyabuga et al. (2009).

\section{Statistical analysis}

Both $M$. fuscoviride and L. hirticornis were analysed as eight subpopulations according to the site of collection. The number of alleles, inbreeding coefficient $\left(F_{\mathrm{IS}}\right)$, global and pairwise $F_{\mathrm{ST}}$ according to Weir \& Cockerham (1984) were calculated in FSTAT version 2.9.3.2 (Goudet, 2002). Observed and expected heterozygosity were calculated in ARLEQUIN version 3.1 (Excoffier et al., 2005). Shared allele distance (DAS) for subpopulations was calculated using POPULATIONS version 1.2.32 (Langella, 1999). Mantel correlation tests for pairwise $F_{\mathrm{ST}}$ and $D A S$ for the two insect species were performed using isolation by distance web service, IBDWS version 3.15 (Jensen et al., 2005). The measure of population differentiation $F_{\mathrm{ST}} /$ $\left(1-F_{\mathrm{ST}}\right)$ developed by Rousset (1997) was used to test for isolation by distance (IBD), also using the IBDWS program. Independent sample Student's t-tests to test for statistical 
Table 1. Localities investigated for Metopeurum fuscoviride and Lysiphlebus hirticornis; $N$ aphids/parasitoids=number of individuals used in analysis; $A$, total number of alleles over all loci; $F_{\mathrm{IS}}$, inbreeding coefficient; $H_{\mathrm{O}}$, observed heterozygosity; and $H_{\mathrm{E}}$, expected heterozygosity.

\begin{tabular}{|c|c|c|c|c|c|c|c|c|c|}
\hline \multirow[t]{2}{*}{ Locality } & \multicolumn{5}{|c|}{ Metopeurum fuscoviride } & \multicolumn{4}{|c|}{ Lysiphlebus hirticornis } \\
\hline & $N$ aphids/parasitoids & $A$ & $F_{\mathrm{IS}}$ & $H_{\mathrm{O}}$ & $H_{\mathrm{E}}$ & $A$ & $F_{\mathrm{IS}}$ & $H_{\mathrm{O}}$ & $H_{\mathrm{E}}$ \\
\hline Jena Nord-1 & 93 & 18 & 0.506 & 0.153 & 0.308 & 55 & 0.401 & 0.309 & 0.514 \\
\hline Göschitz-Bhf & 66 & 13 & 0.766 & 0.027 & 0.116 & 53 & 0.363 & 0.336 & 0.526 \\
\hline Saalbahnhof & 25 & 16 & 0.351 & 0.376 & 0.576 & 40 & 0.285 & 0.313 & 0.435 \\
\hline Fritz-winkler-Str. & 42 & 13 & 0.296 & 0.229 & 0.323 & 46 & 0.452 & 0.286 & 0.519 \\
\hline
\end{tabular}

Table 2. Pairwise $F_{\mathrm{ST}}$ values of each site comparison according to Weir \& Cockerham (1984). Under the diagonal, aphid samples; above diagonal, parasitoid samples.

\begin{tabular}{|c|c|c|c|c|c|c|c|c|}
\hline & $\begin{array}{c}\text { Jena } \\
\text { Nord-1 }\end{array}$ & Burgau-2 & Zwätzen & Göschwitz-Bhf & $\begin{array}{c}\text { Jena } \\
\text { West-Bhf }\end{array}$ & Saalbahnhof & Fritz-winkler-Str. & Porstendorf-Bhf \\
\hline Jena Nord-1 & & 0.1269 & 0.1534 & 0.1316 & 0.1077 & 0.1721 & 0.1142 & 0.1139 \\
\hline Burgau-2 & 0.1039 & & 0.1692 & 0.1214 & 0.0994 & 0.1908 & 0.1960 & 0.1297 \\
\hline Göschwitz-Bhf & 0.0569 & 0.2593 & 0.1394 & & 0.1177 & 0.2161 & 0.1369 & 0.0981 \\
\hline Jena West-Bhf & 0.0982 & 0.0849 & 0.1199 & 0.3032 & & 0.1969 & 0.1398 & 0.0656 \\
\hline Saalbahnhof & 0.3414 & 0.2198 & 0.3242 & 0.5326 & 0.1782 & & 0.2013 & 0.2303 \\
\hline
\end{tabular}

differences and standard regressions in parameters describing populations in each of the sites for $M$. fuscoviride and L. hirticornis were performed in SPSS version 16 (SPSS Inc., 2007).

Statistical analysis was performed on a data set standardized for equal number of aphids and parasitoids at a site. At each of the eight sites, the number of sequenced aphids and parasitoids, respectively, was as follows: Burgau-2 $=61,136$; Fritz-Winkler-Straße =57, 42; Göschwitz-Bhf=113, 66; Jena Nord-1=93, 93; Jena West-Bhf=27, 79; Porstendorf-Bhf =116, 34; Saalbahnhof $=31,25$ and Zwätzen $=28,30$. We used the lower sample number for either aphids or parasitoids sequenced, i.e. Burgau-2 $=61$; Fritz-Winkler-Straße $=42$; Göschwitz-Bhf $=66$; Jena Nord-1=93; Jena West-Bhf $=27$; Porstendorf-Bhf $=34$; Saalbahnhof $=25$ and Zwätzen $=28$. A uniform number for both aphids and parasitoids was obtained by random sampling from all sequenced samples in $R$ ( $R$ Development Core Team, 2008; table 1).

\section{Results}

\section{Alleles}

The total number of alleles per site in aphids ranged from 13 at Göschwitz-Bhf, Fritz-Winkler-Straße and Zwätzen to 21 at Porstendorf, and for parasitoids from 32 at Zwätzen to 55 at Jena Nord-1 (table 1). The total number of alleles in the $M$. fuscoviride subpopulations were not correlated with the total number of alleles in the parasitoid subpopulations $\left(\mathrm{r}=0.022, \mathrm{~F}_{1,7}=0.003, P=0.959\right)$. Alleles per locus averaged $4.176 \pm 0.26$ (SE) in parasitoids and $3.175 \pm 0.19$ (SE) in aphids.
$F_{\text {IS }}$

Samples for both aphids and parasitoids from all sites showed population structures indicative of inbreeding, i.e. positive $F_{\mathrm{IS}}$ (table 1 ). The global $M$. fuscoviride $F_{\mathrm{IS}}$ $(0.505 \pm 0.07 \mathrm{SE})$ was not statistically different from that of L. hirticornis $(0.382 \pm 0.02 \mathrm{SE}, t=1.818, \mathrm{df}=14, P=0.091$, $\mathrm{CI}=-0.2684-0.0222)$. The relationship between aphid $F_{\mathrm{IS}}$ and parasitoid $F_{\text {IS }}$ was also not significant $\left(\mathrm{r}=0.078, \mathrm{~F}_{1,7}=0.037\right.$, $P=0.854)$.

\section{$F_{\mathrm{ST}}$}

Global population genetic differentiation $\left(F_{\mathrm{ST}}\right)$ was $0.171 \pm 0.0014$ (SE) for aphids and statistically different from that of L. hirticornis $(0.142 \pm 0.0003 \mathrm{SE}, t=20.847, \mathrm{df}=14$, $P<0.001, \mathrm{CI}=-0.032$ to -0.026$)$. All pairwise $F_{\mathrm{ST}}$ for both the aphid and parasitoid were statistically different $(P<0.05$; table 2). Pairwise $F_{\mathrm{ST}}$ Mantel correlations revealed that aphid population sub-structuring was positively correlated with that of the parasitoid sub-structuring $(r=0.5240, P=0.067)$. In contrast, when a standard regression method was used, a positive significant value was obtained: vis, $\mathrm{r}=0.524$, $\mathrm{F}_{1,27}=9.841, P=0.004$ (fig. 1 ). Pairwise $F_{\mathrm{ST}} / 1-F_{\mathrm{ST}}$ Mantel test correlations revealed that aphid population sub-structuring was positively, but marginally, non-significantly correlated with that of the parasitoid $(\mathrm{r}=0.5088, P=0.061)$. The DAS between pairs of aphid subpopulations was positively correlated with DAS among parasitoid subpopulations from the same pair of sites (Mantel correlation: $r=0.6697, P=0.040$; fig. 2). 


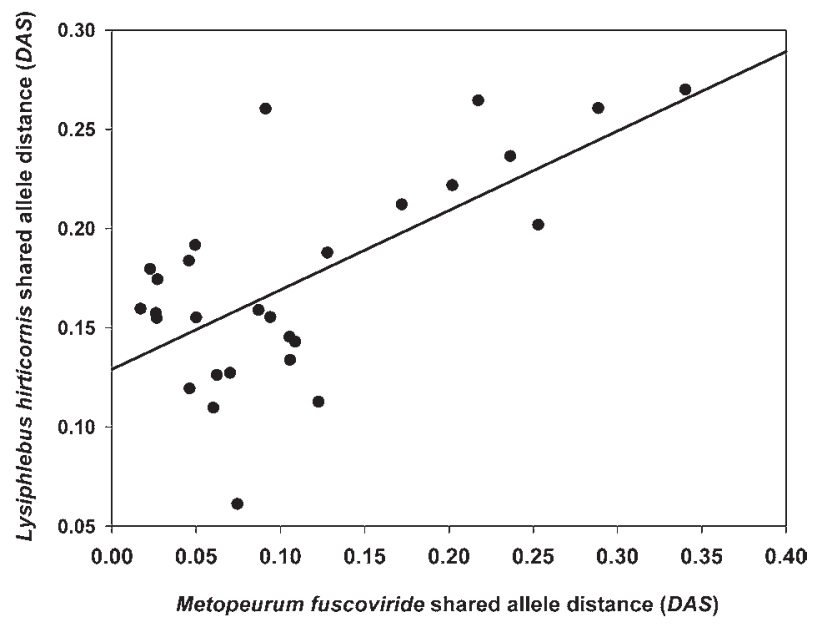

Fig. 2. An increase in population shared allele distance $(D A S)$ in Metopeurum fuscoviride was congruent with an increase in DAS in the parasitoid, Lysiphlebus hirticornis ( $\mathrm{R}=0.670, P=0.040$ ).

\section{Isolation by distance (IBD)}

Mantel tests performed for matrix correlations between genetic distance $\left(F\right.$ st/(1-Fst)) and the logarithm $\left(\log _{10}\right)$ of geographic distance showed no IBD relationship for aphids ( $Z=25.03, r=0.044$, one sided $P=0.453$ from 1000 randomizations) or parasitoids $(Z=17.52, r=-0.224$, one sided $P=0.748$ from 1000 randomizations).

\section{Observed heterozygosity $\left(H_{O}\right)$}

The parasitoid showed a significantly higher level of observed heterozygosity $\left(H_{\mathrm{O}} ; 0.300 \pm 0.01 \mathrm{SE}\right)$ compared with the aphid $(0.195 \pm 0.04 \mathrm{SE}, t=2.621, \mathrm{df}=14, P=0.020$, $\mathrm{CI}=-0.191$ to -0.019$)$. The mean $H_{\mathrm{O}}$ at each site is shown in table 1 . Levels of $H_{\mathrm{O}}$ were not significantly correlated between host and parasitoid $\left(\mathrm{r}=0.226, \mathrm{~F}_{1,7}=0.323, P=0.148\right)$.

\section{Expected heterozygosity $\left(H_{E}\right)$}

$H_{\mathrm{E}}$ levels in L. hirticornis $(0.486 \pm 0.018 \mathrm{SE})$ were higher compared with that of the aphid host, $M$. fuscoviride $(0.369 \pm 0.05 \mathrm{SE} ; t=2.278, \mathrm{df}=14, P=0.039, \mathrm{CI}=-2.228$ to -0.007). Mean $H_{\mathrm{E}}$ values for each site are shown in table 1. Level of $H_{\mathrm{E}}$ were also not significantly correlated between host and parasitoid $\left(\mathrm{r}=-0.561, \mathrm{~F}_{1,7}=2.749, P=0.148\right)$.

\section{Discussion}

Using the qualitative guidelines for genetic differentiation $\left(F_{\mathrm{ST}}\right)$ of Wright (1978), our data show an overall 'greater genetic differentiation' in the aphid host $M$. fuscoviride, which is statistically different from the 'moderate genetic differentiation' in the parasitoid, L. hirticornis. This result may be expected because of the differences in the biology of the insects: $M$. fuscoviride are resident sap sucking herbivores, i.e. they insert their proboscis into the plant phloem and, if undisturbed, continue to feed and reproduce young asexually. The young in turn will start to feed and reproduce on the same plant (Dixon, 1998). In contrast, the parasitoid has free living adults. After emergence from hosts, individual males and females parasitoids may fly or walk from plant to plant in search of mates, and suitable hosts in the case of females (Godfray, 1994). Even though L. hirticornis has fully developed wings, it has not been observed to actively fly but only to walk between aphid colonies on the same genet, i.e. between those on different ramets (Weisser, 2000). On the other hand, as aforementioned, both sexual forms - males and oviparae of $M$. fuscoviride - are wingless (Massonnet, 2002; Loxdale et al., 2010), although migrating winged asexual female morphs (alate exules: Dixon, 1998) have commonly been observed within colonies early in the season as populations build up (Nyabuga, personal observation), probably a response to overcrowding or other stresses as shown in other aphid species (Dixon, 1998; Sloggett \& Weisser, 2002). Given these factors, a higher gene flow and a lowered subpopulation differentiation is expected in the parasitoid compared with the aphid host. Indeed, our results indicate that L. hirticornis has comparatively higher dispersal ability than $M$. fuscoviride, despite its apparent unwillingness or inability to fly. These factors could also be the reason for the comparative differences between the present results and those of Anton et al. (2007). They found moderate differentiation in the Dusky blue butterfly host $M$. nausithous and high differentiation in the parasitoid N. melanocephalus and explained this difference as due to the haplodiploid breeding system of the latter. Predators have often been found to have greater dispersal abilities compared to their hosts (Jones et al., 1996; Brodmann et al., 1997; Ellner et al., 2001).

Since L. hirticornis is a seemingly poor disperser (in terms of active flight at any rate), and some plants within a sites will not be colonized by the parasitoid even when aphids are present (Weisser \& Härri, 2005; Rauch \& Weisser, 2007), it is highly probable that only those host aphid colonies in close proximity are liable to be attacked by the specialized parasitoid, whose breeding system is predominantly philopatric (Nyabuga et al., 2010). Thus, this will tend to cause local inbreeding of the parasitoid (see below).

Subpopulations of $M$. fuscoviride were found to be more genetically related $\left(F_{\mathrm{IS}}=0.505\right)$ to each other compared with values obtained for similar intraspecific comparisons performed for the parasitoid $\left(F_{\mathrm{IS}}=0.382\right)$, and this could be partially also explained by the parthenogenetic mode of reproduction in the aphid host. Aphids reproduce young asexual females with their young within them (i.e. 'telescoping of generations': Dixon, 1998). This reproductive mode may lead to reduced genetic diversity and favour selection for persistent genes. The parasitoid, on the other hand, will only produce females when mated. But because only a few males are produced in a brood, a single male will mate with several females (local mate competition: Hamilton, 1967), which also enhances reduced genetic diversity (Menken, 1991). Due to parthenogenesis, a lower level of genetic diversity in the aphid compared with the haplodiploid parasitoid, therefore, is expected. We report higher total heterozygosity $\left(H_{\mathrm{T}}\right)$ in $L$. hirticornis compared with $M$. fuscoviride. Since allelic richness and genetic diversity are dependent on the number of microsatellite loci (here, five polymorphic loci were used for the aphid compared with 11 for the parasitoid), it is, therefore, not especially meaningful to compare the average number of alleles for genetic diversity directly.

While Mantel test correlations between pairwise $F_{\mathrm{ST}}$, and $\left(F_{\mathrm{ST}} /\left(1-F_{\mathrm{ST}}\right)\right)$ of the host and the parasitoid were marginally non-significant, pairwise DAS for $M$. fuscoviride were positively and significantly correlated with those of L. hirticornis. 
The aphid hosts $M$. fuscoviride always had higher proportion of shared alleles and higher mean $F_{\mathrm{ST}}$ compared to L. hirticornis. Thus, the more genetically similar two host subpopulations were found to be, likewise, the more similar were the parasitoid subpopulations at the same sites and vice versa. The implication of this is that the parasitoid is genetically tracking behind the aphid host. Because parasitoids can only colonize a site if hosts are present and in a system characterized by high turnover due to extinction events as is the case in $M$. fuscoviride-L- hirticornis system (Weisser, 2000; Massonnet, 2002; Nyabuga et al., 2010), then host DAS and $F_{\mathrm{ST}}$ should always be comparatively higher.

Whilst the tansy plants are common enough along the length of the Saale River Valley in Jena, they tend to grow in isolated clumps or stands. These are in effect isolated 'islands' of resource. The only way the aphids can reach these is during the summer migratory phase of the winged asexual migrants (emigrants and immigrants) in response to crowding or lowered food (phloem) quality. Since these aphid morphs, whilst actively flying, are borne on the wind above their low flight speed in still air (Loxdale et al., 1993), only being able to actively orient to individual plants using visual and odour cues below the boundary layer of still air near the ground (Taylor, 1974), it must be difficult for them to land on plants at a distance from their natal plant. Although there was no clear IBD relationship for the aphids or parasitoids over the area sampled (max. $15 \mathrm{~km}$ ), this probably relates to the fact that small numbers of individuals of both insects do manage to land on isolated tansy plants, which prevents clear geographically-based genetic isolation effects at the small scale sampled (see Wang, 2004). Even so, some aphid and some parasitoid subpopulations are, as the present results show, more genetically differentiated than others, within the range shown in table 2. Hence, when and if aphid subpopulations become genetically isolated due to the low probability of colonization within the metapopulation from 'new' winged migrants, and assuming these persist throughout the growing season (and sometimes perhaps between seasons), then it is likely that the philopatric and specialized L. hirticornis remain within such colonies. As a consequence, they tend to become more genetically divergent as a result of bottlenecks and founder events (Nyabuga et al., 2010, 2011).

Whilst it is possible that host and parasitoid colonization of a site occurs independently, there is also the possibility of a proportion of hosts carrying the parasitoid directly within them during migration. Parasitized winged aphids, such as the grain aphid Sitobion avenae (F.), are known to disperse parasitoids in the latter's early stages of development (Walton et al., 2011). We propose that this process occurs frequently, especially when aphid colonies are geographically close to one another, whereupon the probability of aphids finding a suitable new host is probably much enhanced. Also, the plant, aphid and parasitoid have co-evolved with each other, perhaps over millions of years, and thus millions of generations. It is, therefore, not surprising that parasitoid and aphid hosts tend to be fine-tuned genetically to each other over the course of a field season, which in the case of the aphid represents something like 15 asexual generations and one autumnal sexual one (whereupon the sexual forms mate to produce cold hardy overwintering eggs). The process may also perhaps reflect on the Red Queen hypothesis (van Valen, 1973), whereby an 'arms race' exists, maintained by the aphid host trying to evolve away from the attacking parasites, i.e. become more genetically diverse in order to have the adaptive potential to counter the meanwhile co-evolving parasitoid and the immunological response that this engenders (see Loxdale et al., 2011 and references therein).

In conclusion, in a tri-trophic system, where one trophic level is fully dependent on another, as here with the L. hirticornis, M. fuscoviride, tansy system, close coevolutionary associations are bound to occur. Such insect coevolution will, however, almost always be determined by the lower trophic level, in this case the aphid. We have clearly shown that the parasitoid has lower population genetic differentiation compared with the aphid host and seemingly tracks its host, i.e. the more genetically differentiated the aphid subpopulations, so are the parasitoid subpopulations accordingly. That the parasitoid tracks behind the host is likely to be the fundamental mechanism for continued dual metapopulation persistence not only in the M. fuscoviride-L. hirticornis system as here demonstrated, but in host-parasitoid ecological systems generally.

\section{Acknowledgement}

F.N.N. sincerely thanks the Deutscher Akademischer Austausch Dienst (DAAD) for financial support during this study. We also thank the anonymous reviewers for providing helpful editorial comments on the manuscript.

\section{References}

Althoff, D.M. \& Thompson, J.N. (1999) Comparative geographic structures of two parasitoid-host interactions. Evolution 53, 818-825.

Anton, C., Zeisset, I., Musche, M., Durka, W., Boomsma, J.J. \& Settele, J. (2007) Population structure of a large blue butterfly and its specialist parasitoid in a fragmented landscape. Molecular Ecology 16, 3828-3838.

Brodmann, P.A., Wilcox, C.V. \& Harrison, S. (1997) Mobile parasitoids may restrict the spatial spread of an insect outbreak. Journal of Animal Ecology 66, 65-72.

Dixon, A.F.G. (1998) Aphid Ecology. 2nd edn. London, UK, Chapman \& Hall.

Ellner, S.P., McCauley, E., Kendall, B.E., Briggs, C.J., Hosseini, P. R., Wood, S.N., Janssen, A., Sabelis, M.W., Turchin, P., Nisbet, R.M. \& Murdoch, W.W. (2001) Habitat structure and population persistence in an experimental community. Nature 412, 538-543.

Excoffier, L., Laval, G. \& Schneider, S. (2005) Arlequin ver. 3.0: an integrated software package for population genetics data analysis. Evolutionary Bioinformatics Online 1, 47-50.

Godfray, H.C.J. (1994) Parasitoids: Behavioral and Evolutionary Ecology. Princeton, UK, Princeton University Press.

Goudet, J. (2002) FSTAT, A program to estimate and test gene diversities and fixation indices. Version 2.9.3. 2001. Available online at http://www2.unil.ch/popgen/softwares/fstat. htm. Updated from Goudet (1995) (accessed August 2011).

Hamilton, W.D. (1967) Extraordinary sex ratios. Science 156, 477-488.

Jensen, J.L., Bohonak, A.J. \& Kelley, S.T. (2005) Isolation by distance, web service. Bmc Genetics 6, 1-6.

Johannesen, J. \& Seitz, A. (2003) Comparative population genetic structures of the fruit fly Urophora cardui and its primary parasitoid Eurytoma robusta. Entomologia Experimentalis et Applicata 108, 149-157. 
Jones, T.H., Godfray, H.C.J. \& Hassell, M.P. (1996) Relative movement patterns of a tephritid fly and its parasitoid wasps. Oecologia 106, 317-324.

Kankare, M., van Nouhuys, S., Gaggiotti, O. \& Hanski, I. (2005) Metapopulation genetic structure of two coexisting parasitoids of the Glanville fritillary butterfly. Oecologia 143, 77-84.

Kraaijeveld, A.R. \& Van Alphen, J.J.M. (1995) Geographical variation in encapsulation ability of Drosophila melanogaster larvae and evidence for parasitoid specific components. Evolutionary Ecology 9, 10-17.

Kraaijeveld, A.R. \& van der Wel, N.N. (1994) Geographic variation in reproductive success of the parasitoid Asobara tabida in larvae of several Drosophila species. Ecological Entomology 19, 221-229.

Langella, O. (1999) POPULATIONS version 1.2.32. Available online at http://www.bioinformatics.org/project/?group_ id $=84$ (accessed August 2011).

Loxdale, H.D., Hardie, J., Halbert, S., Foottit, R., Kidd, N.A.C. \& Carter, C.I. (1993) The relative importance of short- and longrange movement of flying aphids. Biological Reviews of the Cambridge Philosophical Society 68, 291-311.

Loxdale, H.D., Massonnet, B. \& Weisser, W.W. (2010) Why are there so few aphid clones? Bulletin of Entomological Research 100, 613-622.

Loxdale, H.D., Lushai, G. \& Harvey, J.A. (2011) The evolutionary improbability of 'generalism' in nature, with special reference to insects. Biological Journal of the Linnean Society 103, 1-18.

Loxdale, H.D., Schöfl, G., Wiesner, K.R., Nyabuga, N.N., Heckel, D.G. \& Weisser, W.W. Stay at home aphids: comparative spatial and seasonal metapopulation structure and dynamics of two specialist tansy aphid species studied using microsatellite markers. Biological Journal of the Linnean Society 103, in press (doi: 10.1111/j.10958312.2011.01761.x.).

Mackauer, M. \& Völkl, W. (2002) Brood-size and sex-ratio variation in field populations of three species of solitary aphid parasitoids (Hymenoptera: Braconidae, Aphidiinae). Oecologia 131, 296-305.

Massonnet, B. (2002) Metapopulation structure and population genetics of monophagous aphids on tansy (Tanacetum vulgare L.). PhD thesis, Naturwissenschaftlichen Fakultät Universität Basel, Basel, Switzerland.

Massonnet, B., Leterme, N., Simon, J.C. \& Weisser, W.W. (2002) Characterization of microsatellite loci in the aphid species Metopeurum fuscoviride (Homoptera: Aphididae). Molecular Ecology Notes 2, 127-129.

Menken, S.B.J. (1991) Does haplodiploidy explain reduced levels of genetic variability in Hymenoptera? Proceedings of the Section: Experimental and Applied Entomology of the Netherlands Entomological Society (NEV) 2, 172-178.

Nyabuga, F.N., Loxdale, H.D., Sharbel, T.F., Todd, M. \& Weisser, W.W. (2009) Microsatellites from Lysiphlebus hirticornis Mackauer (Hymenoptera: Braconidae), a specialist primary parasitoid attacking the specialist tansy aphid, Metopeurum fuscoviride Stroyan (Hemiptera: Aphididae). Molecular Ecology Resources 9, 931-934.

Nyabuga, F.N., Loxdale, H.D., Heckel, D.G. \& Weisser, W.W. (2010) Spatial population dynamics of a specialist aphid parasitoid, Lysiphlebus hirticornis Mackauer
(Hymenoptera: Braconidae: Aphidiinae): evidence for philopatry and restricted dispersal. Heredity 105, 433-442.

Nyabuga, F.N., Loxdale, H.D., Heckel, D.G. \& Weisser, W.W. (2011) Temporal genetic structuring of a specialist parasitoid, Lysiphlebus hirticornis Mackauer (Hymenoptera: Braconidae) attacking a specialist aphid on tansy. Biological Journal of the Linnean Society 102, 737-749.

Nyabuga, F.N., Völkl, W., Schwörer, U., Weisser, W.W. \& Mackauer, M. Mating strategies in solitary aphid parasitoids: effect of patch residence time and ant attendance. Journal of Insect Behavior, in press (doi: 10.1007/s10905-011-9279-3).

Polaszek, A. (1986) The effects of two species of hymenopterous parasitoid on the reproductive system of the pea aphid, Acyrthosiphon pisum. Entomologia Experimentalis et Applicata 40, 285-292.

R Development Core Team (2008) R: A language and environment for statistical computing. Vienna, Austria, R Foundation for Statistical Computing.

Rauch, G. \& Weisser, W.W. (2007) Local and spatial dynamics of a host-parasitoid system in a field experiment. Basic and Applied Ecology 8, 89-95.

Rousset, F. (1997) Genetic differentiation and estimation of gene flow from $F$-statistics under isolation by distance. Genetics 145, 1219-1228.

Sloggett, J.J. \& Weisser, W.W. (2002) Parasitoids induce production of the dispersal morph of the pea aphid, Acyrthosiphon pisum. Oikos 98, 323-333.

SPSS Inc. (2007) SPSS base 16.0 for windows user's guide. Chicago, IL, USA, SPSS Inc.

Sunnucks, P. \& Hales, D.F. (1996) Numerous transposed sequences of mitochondrial cytochrome oxidase I-II in aphids of the genus Sitobion (Hemiptera: Aphididae). Molecular Biology and Evolution 13, 510-524.

Taylor, L.R. (1974) Insect migration, flight periodicity and boundary layer. Journal of Animal Ecology 43, 225-238.

Thompson, J.N. (1994) The Coevolutionary Process. Chicago, IL, USA, University of Chicago.

van Valen, L. (1973) A new evolutionary law. Evolutionary Theory 1, 1-30.

Walton, M.P., Loxdale, H.D. \& Allen-Williams, L.J. (2011) Flying with a 'death sentence' on board: electrophoretic detection of braconid parasitoid larvae in migrating winged grain aphids, Sitobion avenae (F.). Bulletin of Entomological Research 101, 443-449.

Wang, J.L. (2004) Application of the one-migrant-per-generation rule to conservation and management. Conservation Biology 18, 332-343.

Weir, B.S. \& Cockerham, C.C. (1984) Estimating F-statistics for the analysis of population structure. Evolution 38, 1358-1370.

Weisser, W.W. (2000) Metapopulation dynamics in an aphidparasitoid system. Entomologia Experimentalis et Applicata 97, 83-92.

Weisser, W.W. \& Härri, S.A. (2005) Colonisations and extinctions at multiple spatial scales: a case study in monophagous herbivores. Annales Zoologici Fennici 42, 363-377.

Wright, S. (1978) Evolution and Genetics of Populations: Variability within and among Natural Populations. Chicago, IL, USA, University of Chicago.

Zheng, C.Z., Weisser, W.W., Harri, S.A. \& Ovaskainen, O. (2009) Hierarchical metapopulation dynamics of two aphid species on a shared host plant. American Naturalist 174, 331-341. 